Supporting Information

Journal of Physical Chemistry B

\title{
Geometry and Solvent Dependence of the Electronic Spectra of the Amide Group and Consequences for Peptide Circular Dichroism.
}

\author{
Jiří Šebek, Zdeněk Kejík and Petr Bouř
}

\begin{abstract}
This material contains detailed parameters of the combined ab initio/transition dipole coupling model for simulations of the peptide ECD spectra (Tables 1s-2s, Figure 2s), relative permittivity dependence of NMA transitions (Figure 1s), and some examples of experimental spectra of peptides and proteins.
\end{abstract}


TABLE 1s: Comparison of Calculated (Becke3LYP/6-311++G**) Wavelengths and Transition Dipoles in NMA in Vacuum and in Water Clusters Surrounded by Dielectric Continuum (COSMO Solvent Model)

\begin{tabular}{lccccccc}
\hline & $\lambda_{\mathrm{VAC}}{ }^{\mathrm{a}}$ & $\lambda_{\mathrm{SOL}}{ }^{\mathrm{a}}$ & $\lambda_{\mathrm{RMS}}{ }^{\mathrm{a}}$ & $\mathrm{D}_{\mathrm{VAC}}{ }^{\mathrm{b}}$ & $\mathrm{D}_{\mathrm{SOL}}{ }^{\mathrm{b}}$ & $\mathrm{D}_{\mathrm{RMS}}{ }^{\mathrm{b}}$ & $\delta \tau^{\mathrm{b}}$ \\
\hline $1 \mathrm{~A}^{\prime}$ & 217 & 202 & 16 & 0.03 & 0.06 & 0.12 & 38 \\
$2 \mathrm{~A}^{\prime}$, & 216 & 209 & 10 & 0.00 & 0.08 & 0.11 & 48 \\
$3 \mathrm{~A}^{\prime}$ & 214 & 193 & 22 & 0.55 & 0.47 & 0.72 & 31 \\
$4 \mathrm{~A}^{\prime}$ & 191 & 169 & 22 & 0.57 & 0.79 & 1.74 & 55 \\
$5 \mathrm{~A}^{\prime}$, & 190 & 179 & 12 & 0.38 & 1.68 & 2.27 & 59 \\
$6 \mathrm{~A}^{\prime}$ & 183 & 179 & 9 & 0.56 & 0.66 & 0.78 & 50 \\
$7 \mathrm{~A}^{\prime}$, & 182 & 188 & 12 & 0.28 & 0.68 & 0.77 & 42 \\
$8 \mathrm{~A}^{\prime}$ & 176 & 183 & 7 & 3.35 & 2.67 & 4.86 & 12 \\
9A', & 175 & 168 & 10 & 0.00 & 0.27 & 0.44 & 68 \\
$10 \mathrm{~A}^{\prime}$ & 175 & 175 & 9 & 2.68 & 2.63 & 2.38 & 29 \\
\hline
\end{tabular}

${ }^{a}$ Wavelengths (nm) in vacuum (VAC), averages (SOL) and root mean square deviations (RMS) obtained for 90 NMA-water clusters.

${ }^{\mathrm{b}}$ Dipole strengths in debye $\mathrm{e}^{2} . \delta \tau\left(^{\circ}\right)$ is average angle deviation between the vacuum and cluster transition dipole vectors. 
TABLE 2s: Electric Transition Dipole Moment Vectors for NMA in Vacuum (Becke3LYP/6-311++G**) and Average Vectors ${ }^{\mathrm{a}}$ for NMA/Water Clusters Surrounded by the COSMO Dielectric Continuum

\begin{tabular}{cccccrrr}
\hline Transition & $\lambda_{\text {VAC }}(\mathrm{nm})$ & $\mu_{\mathrm{X}, \mathrm{VAC}}$ & $\mu_{\mathrm{Y}, \mathrm{VAC}}$ & $\mu_{\mathrm{Z}, \mathrm{VAC}}$ & \multicolumn{1}{c}{$\mu_{\mathrm{X}, \mathrm{SOL}}$} & \multicolumn{1}{c}{$\mu_{\mathrm{Y}, \mathrm{SOL}}$} & $\mu_{\mathrm{Z}, \mathrm{SOL}}$ \\
\hline 1 & 217 & 0.0000 & 0.0000 & 0.1751 & 0.0069 & 0.0007 & 0.0949 \\
2 & 216 & 0.0000 & 0.0000 & -0.0236 & 0.008 & -0.0201 & -0.1058 \\
3 & 214 & 0.2092 & 0.7142 & 0.0000 & 0.085 & 0.2552 & -0.0088 \\
4 & 191 & -0.2720 & -0.7074 & 0.0000 & 0.0488 & -0.3456 & 0.0016 \\
5 & 190 & 0.0000 & 0.0000 & -0.6179 & 0.0812 & -0.1907 & -0.4664 \\
6 & 183 & 0.3907 & 0.6359 & 0.0000 & -0.0417 & 0.3151 & -0.0251 \\
7 & 182 & 0.0000 & 0.0000 & -0.5310 & -0.0357 & -0.024 & -0.3226 \\
8 & 176 & 0.9732 & -1.5489 & 0.0000 & 0.4491 & -0.9431 & -0.0158 \\
9 & 175 & 0.0000 & 0.0000 & -0.0549 & 0.0194 & 0.0422 & -0.1972 \\
10 & 175 & -0.1131 & -1.6321 & 0.0000 & 0.132 & -0.6244 & -0.0017 \\
\hline
\end{tabular}

a Average dipole lengths were projected into average vector directions. Atomic dipole units are used. Local NMA magnetic dipoles were neglected.

Following reference NMA geometry was used for all calculations:

\begin{tabular}{rrrr}
\hline $\mathrm{O}$ & -1.176 & 0.851 & 0 \\
$\mathrm{C}$ & 0 & 0.511 & 0 \\
$\mathrm{~N}$ & 0.398 & -0.799 & 0 \\
$\mathrm{H}$ & 1.384 & -1.006 & 0 \\
$\mathrm{C}$ & -0.548 & -1.899 & 0 \\
$\mathrm{C}$ & 1.128 & 1.532 & 0 \\
$\mathrm{H}$ & -1.548 & -1.462 & 0 \\
$\mathrm{H}$ & -0.432 & -2.527 & 0.891 \\
$\mathrm{H}$ & -0.432 & -2.527 & -0.891 \\
$\mathrm{H}$ & 2.129 & 1.092 & 0 \\
$\mathrm{H}$ & 1.021 & 2.171 & -0.880 \\
$\mathrm{H}$ & 1.021 & 2.171 & 0.880 \\
\hline
\end{tabular}



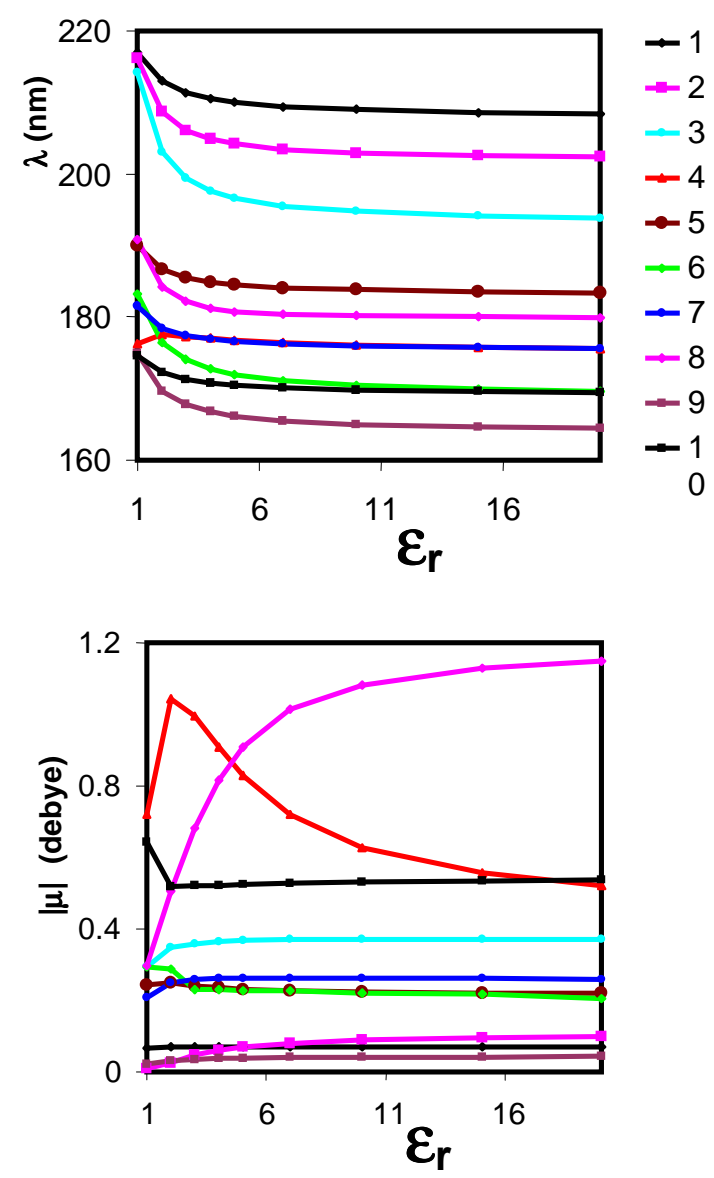

Figure 1s. The dependences of transition wavelengths (top) and electric dipoles (bottom) of the amide group on the solvent relative permittivity $\left(\varepsilon_{\mathrm{r}}\right)$, obtained with the COSMO/B3LYP/6-311++G**solvent model for NMA. 

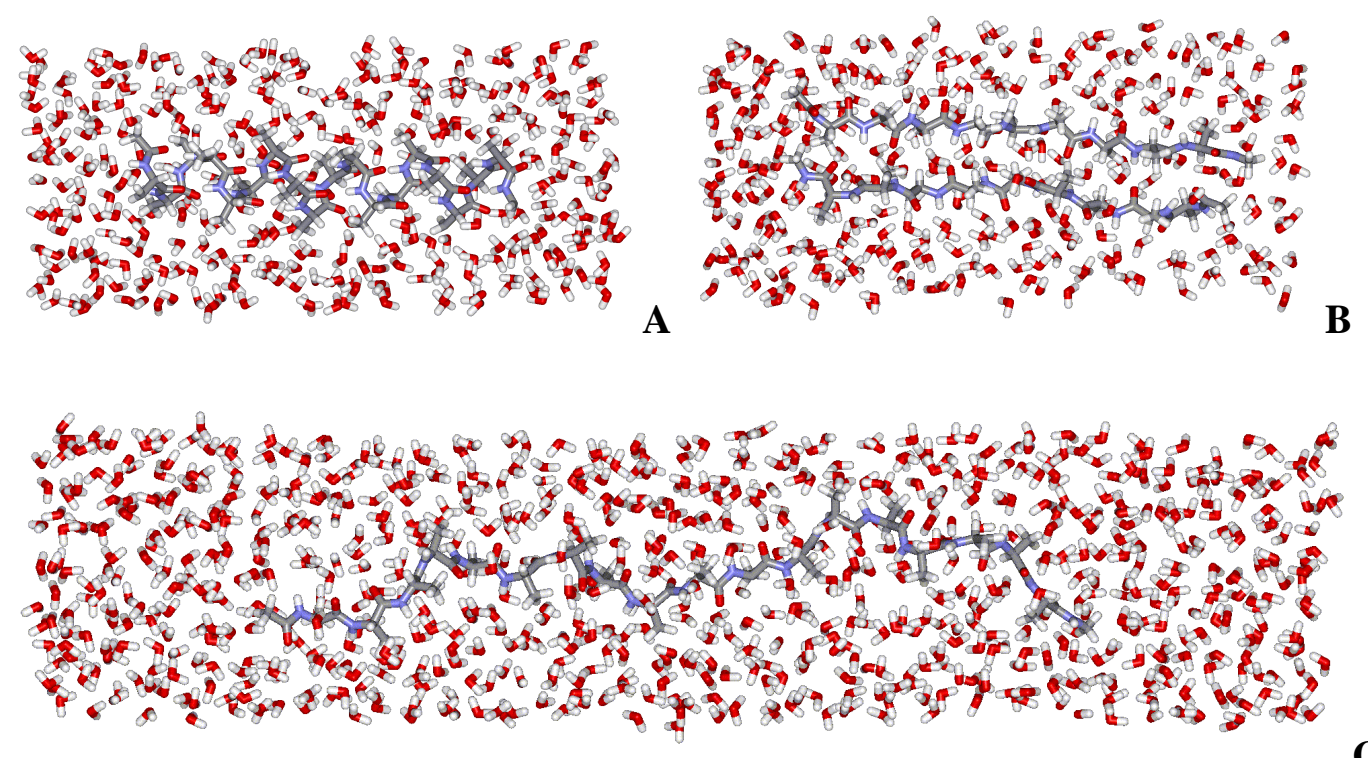

Figure 2s. The systems used for molecular dynamics and CD spectra simulations of standard peptide forms: (A) $\alpha$-helical 19 -amide in a $45 \times 20 \times 20 \AA$ periodic box, (B) $2 \times 10$ amide anti-parallel $\beta$-peptide in a $45 \times 20 \times 20 \AA$ box and $(\mathrm{C})$ the 19 -amide in a random-coil (polyproline II like) conformation, with a $90 \times 20 \times 20 \AA ̊$ box. Some water molecules in the boxes in front of the peptides are not visible in this figure. 


\section{Experimental peptide ECD spectra taken from literature}
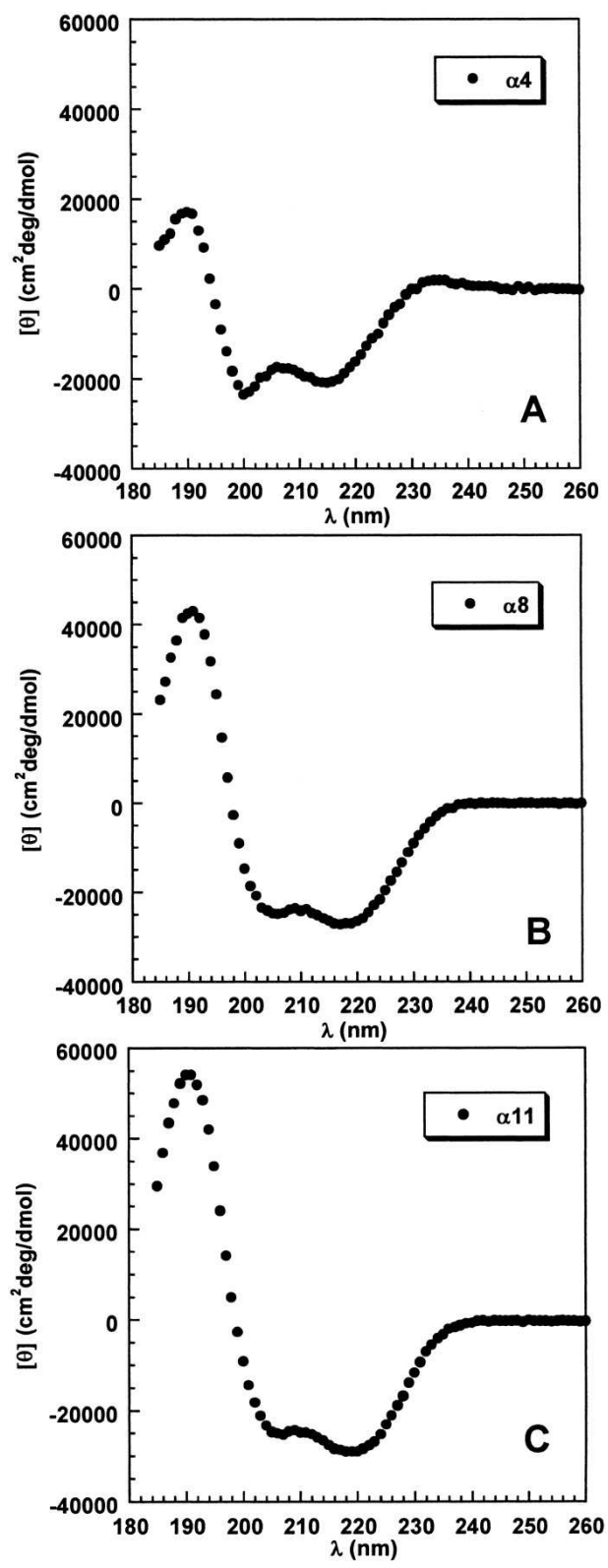

CD spectra taken in $0.1 \mathrm{M} \mathrm{NaClO}_{4}, 4^{\circ} \mathrm{C}$, of the helical segment (with $\mathrm{La}^{3+}$ ) of peptide $\mathrm{P} 1$ $(A), \mathrm{P} 2(B)$, and $\mathrm{P} 3(C)$. The ordinate shows mean peptide ellipticity per helical peptide unit, assuming four helical peptide units in P1, eight in P2, and 11 in P3. 
Reproduced from: Chin, D. H.; Woody, R. W.; Rohl, A. C.; Baldwin, R. L.Proc. Natl. Acad. Sci. U. S. A. 2002, 99 (24), 15416-15421,"Circular dichroism spectra of short, fixed-nucleus alanine helices."

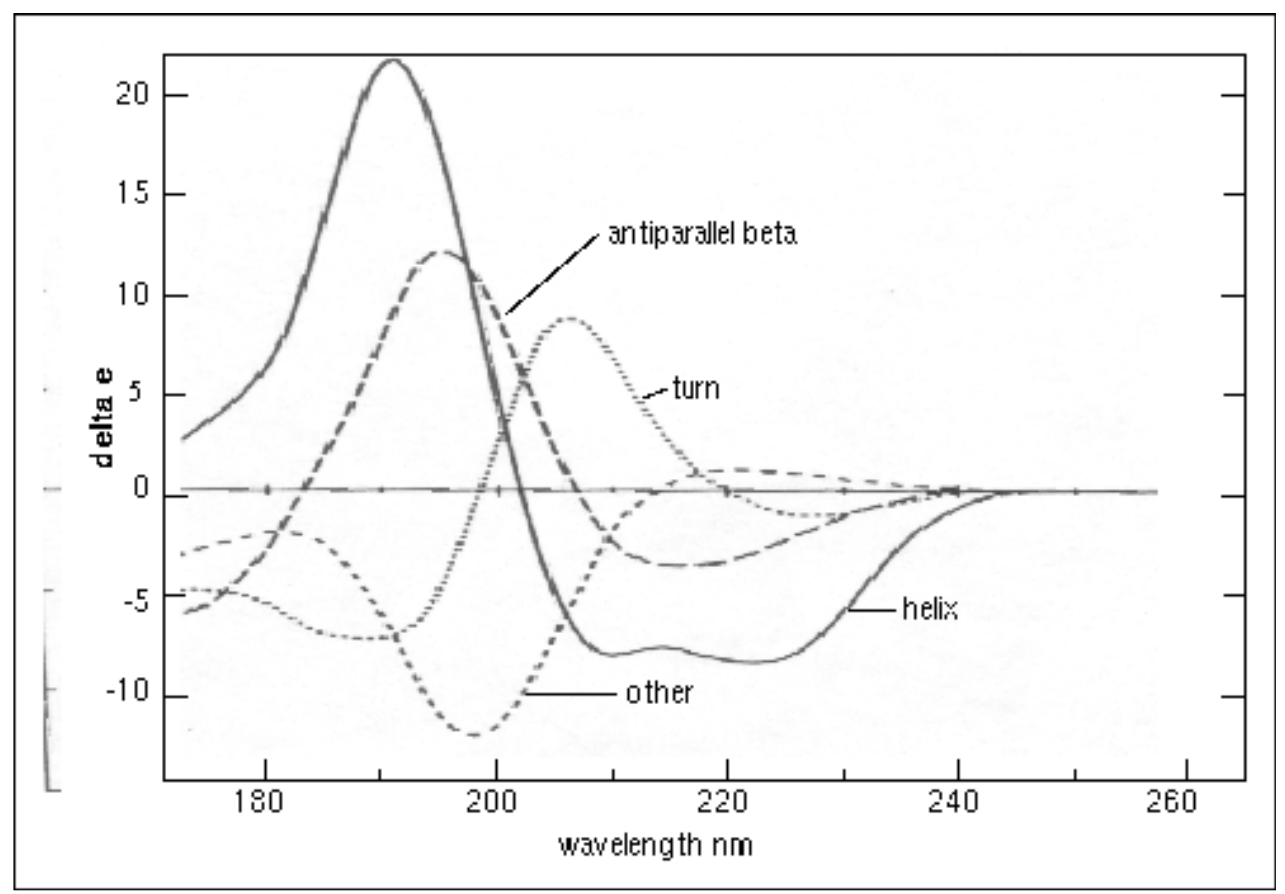

Circular dichroism spectra of "pure" secondary structures.

Reproduced from: Brahms, S.; Brahms, J.J. Mol. Biol. 1980, 138 (2), 149-178, "Determination of protein secondary structure in solution by vacuum ultraviolet circular dichroism." 


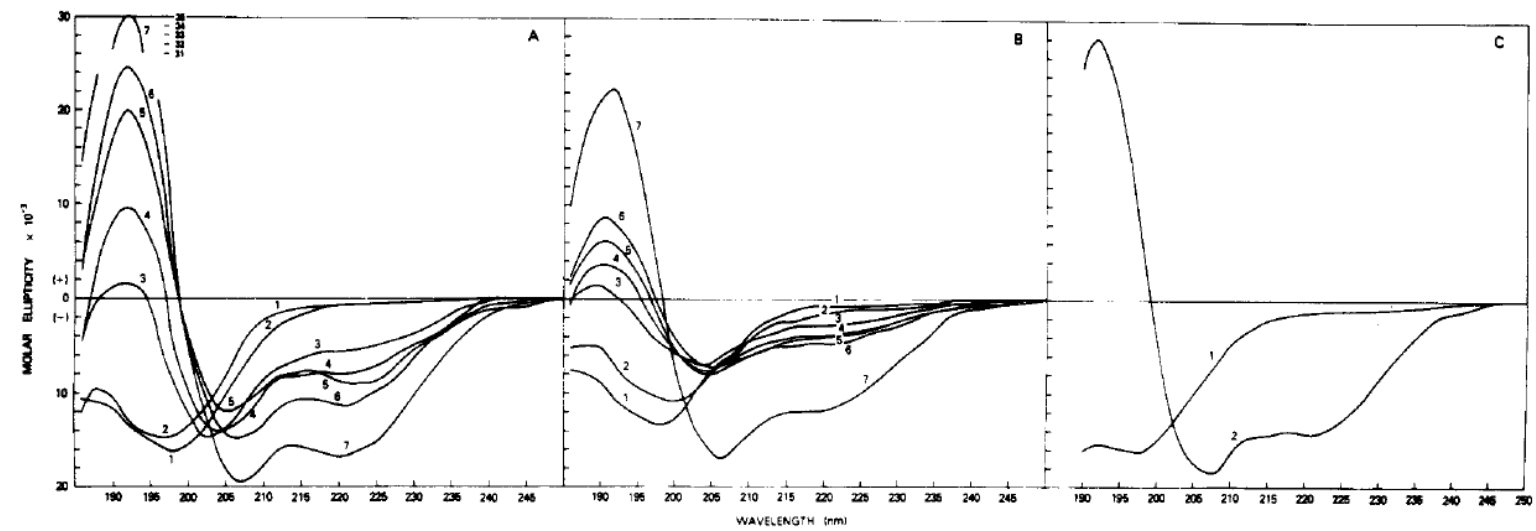

FIGURE 1: Low-ultraviolet CD spectra of MBP and MBP-derived oligopeptides in 0-92\% TFE. (A) Peptide 1-95: curves 1, 2, 3, 4, 5, 6, and 7 represent $0 \%, 10 \%, 20 \%, 30 \%, 50 \%, 75 \%$, and $92 \%$ TFE, respectively. (B) Peptide 96-168: same line code as for (A). (C) MBP: curve $1,0 \%$ TFE; curve $2,92 \%$ TFE.

Reproduced from: Stone, A. Larack; Park, J. Y.; Martenson, R. E. Biochemistry 1985, 24, 666-6673. "Low-Ultraviolet Circular Dichroism Spectroscopy of Oligopeptides 1-95 and 96-168 Derived from Myelin Basic Protein of Rabbit." 


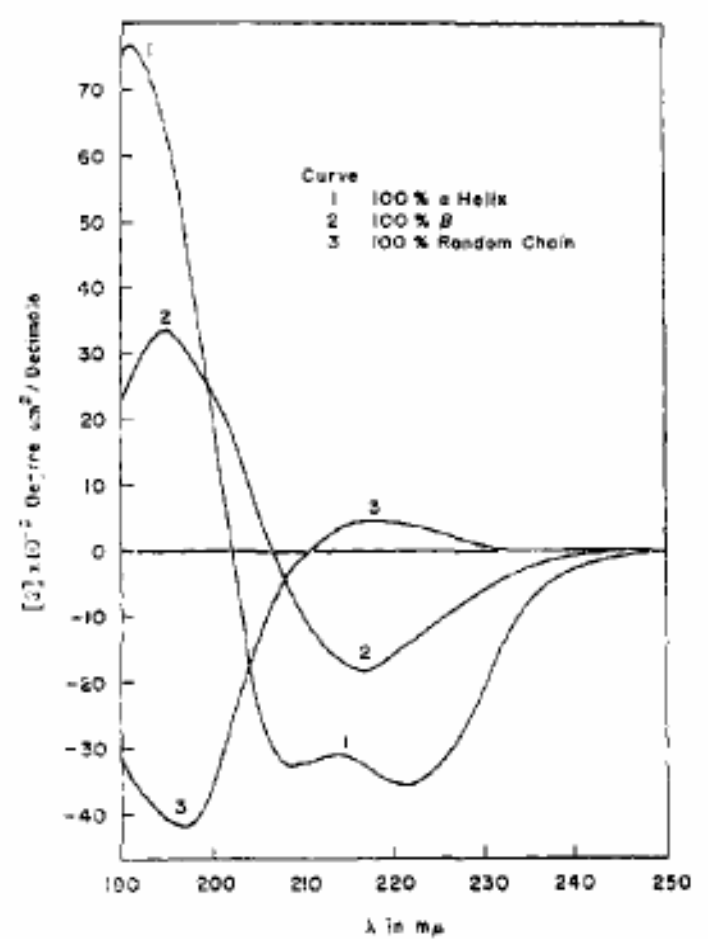

ECD Spectra of Poly-L-Lysine Forms.

Reproduced from: Greenfield, N., B. Davidson, G. D. Fasman. Biochemistry 1967, 6, 1630-1637," The use of computed optical rotatory dispersion curves for the evaluation of protein conformation"; Greenfield, N., G. D. Fasman. Biochemistry 1969, 8, 4108-4116. "Computed circular dichroism spectra for the evaluation of protein conformation." 


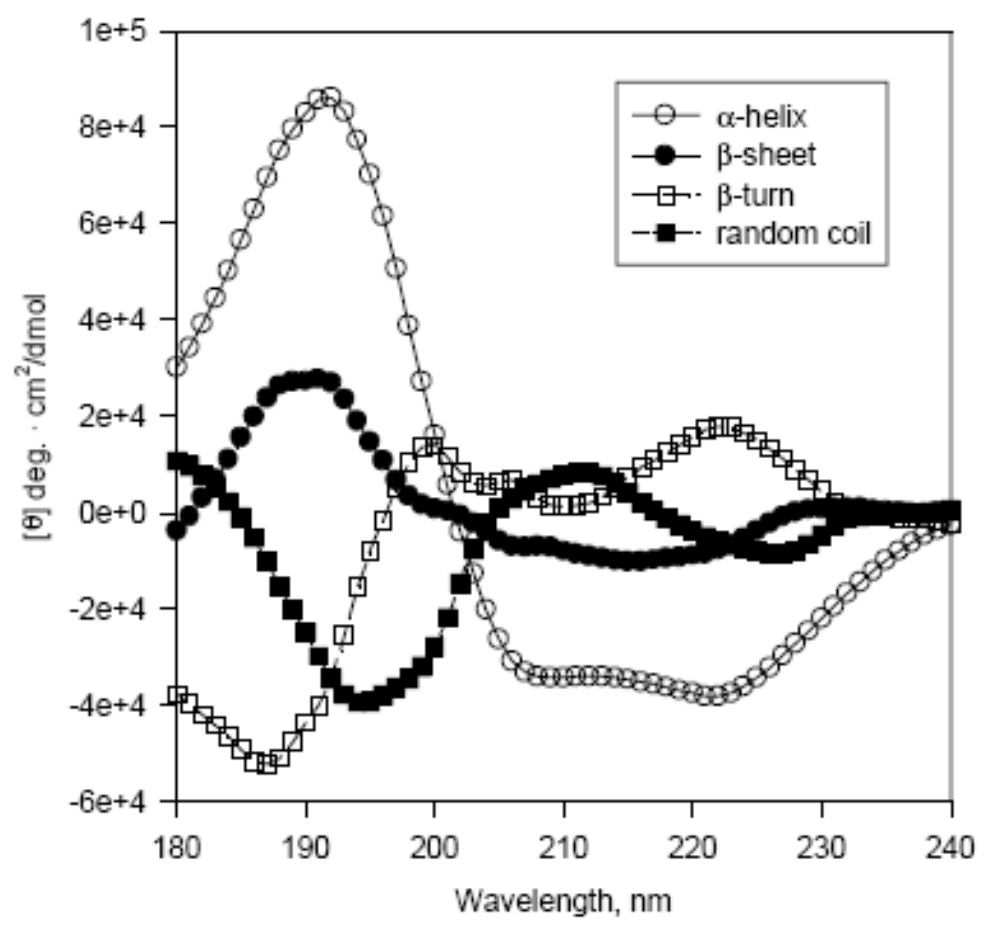

Fig. 19. CD basic spectra extracted from the spectra of 16 protein plus poly-L-glutamate by the method of least squares.

Reproduced from: Yang, J. T., C. S. Wu, H. M. Martinez. Methods Enzymol. 1986, 130, 208-269, "Calculation of protein conformation from circular dichroism." 